\title{
Professor Sir David Todd
}

Hong Kong Med J 2017;23:541

DOI: $10.12809 / \mathrm{hkmj} 175073$

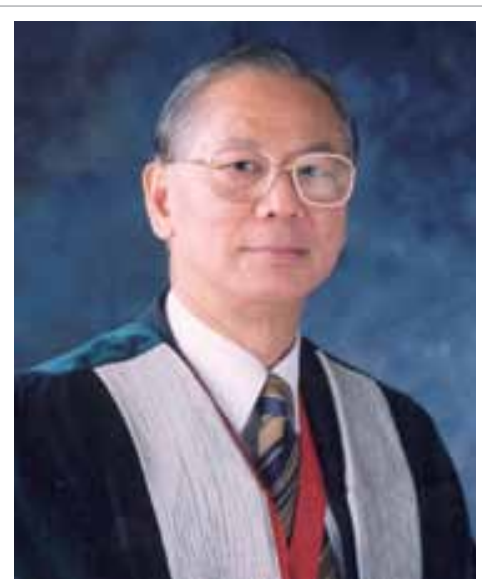

Professor Sir David Todd (1928-2017)
Professor Sir David Todd, Founding President of the Academy, passed away peacefully after a brief illness on 16 August 2017 at Queen Mary Hospitalwhere his medical education matured and exceptional career achievement endured. He was taken care of by those he had taught and surrounded by his family, beloved students and mentees.

Widely revered by the medical profession in Hong Kong and internationally for his achievements in medical education and research, Sir David also had an unassailable reputation for his selfless dedication to patient care and numerous community services.

Sir David was instrumental in the establishment of the Hong Kong Academy of Medicine (HKAM). He was Chairman of the HKAM Preparatory Committee from 1990 to 1992 and served the Academy as her founding President between 1992 and 1996. After stepping down from his Presidency, Sir David continued to give support to the Academy Council and offered advice. To honour his contribution, the Executive Board of the HKAM Foundation Fund proposed in 1995 to organise an Oration in the name of Sir David to be held annually at the Academy. In 1997, Sir David was further elected an Honorary Fellow of the Academy.

Professor Todd, as many of us used to fondly call him, was regarded a formidable and caring teacher and mentor by his students and colleagues and commanded tremendous respect from the medical community in Hong Kong.

"There is more to a good medical and dental practitioner than the ability to pass examinations: compassion and wisdom must be added to expertise." He once wrote in the foreword of the Academy's Tenth Anniversary Commemorative Book.

In his 2014 speech at the first dinner gathering organised for Council members and Past Presidents to meet with distinguished Young Fellows, Prof Todd said:

You are a specially gifted group and with this come obligations. These include being leaders in preventing and treating disease, carrying out research to advance health care, sharing your knowledge with colleagues, especially those who follow in your footsteps, educating the public and placing service before self-interest. In other words honour professionalism, and be role models. Some of your work can be done through the Academy and its Colleges and I hope you will actively contribute to their endeavours.

Hong Kong is going through difficult times. You face more challenges than we did in the past. But Hong Kong has survived and thrived. The medical profession traditionally shies away from politics but we may no longer be able to do so. Come what may the integrity of our profession must be maintained. I trust you can strike a balance between idealism and reality. Einstein said "Life is like riding a bicycle. To keep your balance you must keep moving". So do keep moving in the right direction and uphold the profession......

Besides his work in the Academy, he had contributed immensely to the development and growth of medicine in the city and beyond. He was Head of the University of Hong Kong Department of Medicine from 1974 to 1989, Founding President of the Hong Kong College of Physicians in 1986, and a member of the first Hospital Authority Board in 1990. He was also Chairman of the AIDS Trust Fund, Chairman of the Health Services Research Committee, Vice-Chairman of the S.K. Yee Medical Foundation, and Trustee of the Croucher Foundation and the Sino-British Fellowship Trust.

Prof Todd also emphasised the importance of research in medical education and training, commenting that "it focuses the mind, increases analytical powers, and contributes to improvements in health and patient care." Between 1986 and 1993, Prof Todd served on the University and Polytechnic Grants Committee and was the first Chairman of its Research Grants Committee.

Sir David had received numerous local and overseas College Fellowships and awards over the years with the Carl de Grouchy Medal awarded by the Haematology Society of Australia in 1979 among the most notable ones. For his services to medicine and education in Hong Kong, he was awarded an Officer (OBE), a Commander (CBE), and Knight Bachelor of the Most Excellent Order of the British Empire in 1982, 1990, and 1995, respectively.

Sir David has left behind a legacy of love, respect, leadership and, most importantly, humanism. He will be always remembered by his family, friends, colleagues, students, and staff.

CS Lau

President

Hong Kong Academy of Medicine 